\title{
Potential impacts of cold frontal passage on air quality over the Yangtze River Delta, China
}

\author{
Hanqing Kang ${ }^{1,2,3,4}$, Bin $\mathrm{Zhu}^{1,2,3,4}$, Jinhui Gao ${ }^{5}$, Yao $\mathrm{He}^{6}$, Honglei Wang ${ }^{1,2,3,4}$, Jifeng $\mathrm{Su}^{7}$, Chen Pan ${ }^{1,2,3,4}$, \\ Tong $\mathbf{Z h u}^{8,9}$, and Bu Yu${ }^{10}$ \\ ${ }^{1}$ Collaborative Innovation Center on Forecast and Evaluation of Meteorological Disasters, \\ Nanjing University of Information Science and Technology, Nanjing, China \\ ${ }^{2}$ Key Laboratory for Aerosol-Cloud-Precipitation of China Meteorological Administration, \\ Nanjing University of Information Science and Technology, Nanjing, China \\ ${ }^{3}$ Key Laboratory of Meteorological Disaster, Ministry of Education (KLME), \\ Nanjing University of Information Science and Technology, Nanjing, China \\ ${ }^{4}$ Joint International Research Laboratory of Climate and Environment Change (ILCEC), \\ Nanjing University of Information Science and Technology, Nanjing, China \\ ${ }^{5}$ Department of Ocean Science and Engineering, Southern University of Science and Technology, Shenzhen, China \\ ${ }^{6}$ Baoji Meteorological Bureau, Baoji, China \\ ${ }^{7}$ The 61 Squad of the 94857 Unit of People's Liberation Army, Wuhu, China \\ ${ }^{8}$ CIRA, Colorado State University, Fort Collins, Colorado, USA \\ ${ }^{9}$ NOAA/NESDIS/STAR/JSCDA, College Park, Maryland, USA \\ ${ }^{10}$ Hangzhou Meteorological Bureau, Hangzhou, China
}

Correspondence: Bin Zhu (binzhu@ nuist.edu.cn)

Received: 12 June 2018 - Discussion started: 30 October 2018

Revised: 20 February 2019 - Accepted: 26 February 2019 - Published: 21 March 2019

\begin{abstract}
Cold frontal passages usually promote quick removal of atmospheric pollutants over North China (e.g. the Beijing-Tianjin-Hebei region). However, in the Yangtze River Delta (YRD), cold fronts may bring air pollutants from the polluted North China Plain (NCP), thereby deteriorating the air quality in the YRD. In this study, a cold frontal passage and a subsequent stable weather event over YRD during 21-26 January 2015 was investigated with in situ observations and Weather Research and Forecasting - Community Multiscale Air Quality Modeling System simulations. Observations showed a burst of $\mathrm{PM}_{2.5}$ pollution and an obvious southward motion of $\mathrm{PM}_{2.5}$ peaks on the afternoon of 21 January, suggesting a strong inflow of highly polluted air masses to YRD by a cold frontal passage. Model simulations revealed an existing warm and polluted air mass over YRD ahead of the frontal zone, which climbed to the free troposphere along the frontal surface as the cold front passed, increasing the $\mathrm{PM}_{2.5}$ concentration at high altitudes. Strong north-westerly frontal airflow transported particles from the
\end{abstract}

highly polluted NCP to the YRD. As the frontal zone moved downstream of YRD, high pressure took control over the YRD, which resulted in a synoptic subsidence that trapped $\mathrm{PM}_{2.5}$ in the boundary layer. After the cold frontal episode, a uniform pressure field took control over the YRD. Locally emitted $\mathrm{PM}_{2.5}$ started to accumulate under the weak winds and stable atmosphere. Tagging of $\mathrm{PM}_{2.5}$ by geophysical regions showed that the $\mathrm{PM}_{2.5}$ contribution from the YRD itself was $35 \%$ and the contribution from the NCP was $29 \%$ during the cold frontal passage. However, under the subsequent stable weather conditions, the $\mathrm{PM}_{2.5}$ contribution from the YRD increased to $61.5 \%$ and the contribution from the NCP decreased to $14.5 \%$. The results of this study indicate that cold fronts are potential carriers of atmospheric pollutants when there are strong air pollutant sources in upstream areas, which may deteriorate air quality in downstream regions. 


\section{Introduction}

Fast economic development and urbanization processes in China have led to an increase in air pollution during the past few decades (Han et al., 2016; Chen and Wang, 2015; Cao et al., 2015). Haze, which is formed by fine particulate extinction, has been the most prevalent atmospheric pollution phenomenon over China in recent years (Huang et al., 2014; Wang et al., 2017). The fundamental cause of haze is an increase in particulate matter - especially fine particles - with aerodynamic diameters equal to or less than $2.5 \mu \mathrm{m}\left(\mathrm{PM}_{2.5}\right)$. Recently, fine particulate matter has caused wide concern owing to its impacts on regional air quality (Z. Wang et al., 2013), human health (Gao et al., 2017), and climate change (Rosenfeld et al., 2014).

Densely populated city clusters in China (e.g. the BeijingTianjin-Hebei, BTH, region; Yangtze River Delta, YRD; and Pearl River Delta, PRD) are associated with heavy particle pollution (Z. Wang et al., 2013; Liao et al., 2015; Wu et al., 2007). The two largest city clusters, BTH and YRD, are geographically close to each other. Significant cross-border transport of $\mathrm{PM}_{2.5}$ has occurred between BTH and YRD ( $\mathrm{Li}$ et al., 2013). Cold fronts promote the long-range transport of dust and anthropogenic air pollutants (Liu, 2003; Mari, 2004) that are usually favourable for the quick removal of atmospheric pollutants in BTH (Zhao et al., 2013; Gao et al., 2016). Meanwhile, the YRD is located south of BTH, where cold fronts may transport pollutants from BTH to YRD and exacerbate atmospheric pollution. This indicates that the control of emissions in one city cluster is not sufficient to reduce particulate pollution; joint efforts among city clusters are crucial.

The formation mechanisms of $\mathrm{PM}_{2.5}$ pollution in China remain highly uncertain owing to complex interactions among pollution sources, meteorology, and atmospheric chemical processes (Guo et al., 2014). Generally, high emission intensity, adverse meteorological conditions, secondary aerosol formation, and the regional transport of particles are main factors contributing to the formation of particulate pollution (Sun et al., 2013; Wang et al., 2014; Y. Wang et al., 2013; Li et al., 2013). As anthropogenic emissions do not vary much from day to day, particulate pollution episodes are more often associated with adverse meteorological conditions, such as weak surface winds, stable stratified conditions, low mixing layers, and winds from particle source regions that transport large volumes of particles (Tao et al., 2014; Y. Wang et al., 2013; J. Li et al., 2017). Under such weather conditions, substantial amounts of secondary aerosols can be generated and aggravate particulate pollution (Gao et al., 2015; Huang et al., 2014).

Particulate concentrations have been decreasing since 2013 owing to implementation of the Atmospheric Pollution Prevention and Control Action Plan (Wei et al., 2017). However, particle pollution episodes remain frequent, especially in the wintertime. Under the influence of the East Asia winter monsoon, the YRD is dominated by cold air activity in the wintertime. If cold air activity intensified, cold fronts would intrude into the YRD. In contrast, after a cold frontal passage, weakened winds and a stable atmosphere remain over the YRD. A regional-scale stationary atmosphere is unfavourable for the diffusion of pollutants and leads to haze events, a phenomenon that has been extensively studied over East China (Yang et al., 2015; Z. Wang et al., 2013; Y. Wang et al., 2013; Leng et al., 2016). Lin et al. (2007) suggested that long-range transport of Asian dust and upstream air pollutants by cold fronts are important environmental issues of Taiwan during the winter monsoon season. Liu (2003) pointed out that the major process driving Asian pollution outflow in spring is frontal lifting ahead of southeastward-moving cold fronts and transport in the boundary layer behind the cold fronts. Therefore, cold fronts may have a significant impact on air quality along its transport pathway.

In this study, we employed the Weather Research and Forecasting (WRF) mesoscale meteorological model and the Community Multiscale Air Quality Modelling System (CMAQ) to investigate the sources and formation processes of $\mathrm{PM}_{2.5}$ pollution during a cold frontal passage and subsequent stable weather conditions in January 2015 . We investigated the formation processes, horizontal distributions, vertical structures, and contributions from source regions to $\mathrm{PM}_{2.5}$ over the YRD in both synoptic patterns. Our results highlight the reasons behind high $\mathrm{PM}_{2.5}$ episodes and source contributions to $\mathrm{PM}_{2.5}$ over the YRD and will be helpful to policy-makers in this region.

\section{Model description and verification}

\subsection{Configuration of weather prediction model}

The numerical model used in this study was the nonhydrostatic, compressible, two-way interactive Advanced Research WRF (version 3.4; Skamarock et al., 2008) coupled with a single-layer urban canopy model (Kusaka et al., 2001; Chen et al., 2004). The simulation domain includes geographical areas (e.g. East China and the Korean Peninsula) with $10 \mathrm{~km} \times 10 \mathrm{~km}$ horizontal resolution and $220 \times 220$ grids, centred at $33.5^{\circ} \mathrm{N}$ and $118^{\circ} \mathrm{E}$ (Fig. 1). The vertical grid contains 30 full sigma levels from the surface to $50 \mathrm{hPa}$, the lowest 20 levels of which are below $2 \mathrm{~km}$ to better resolve processes within the boundary layer. The WRF interior grid-nudging technique was used to improve meteorological fields simulation. An 18-day simulation (from 00:00 UTC 10 January 2015 to 00:00 UTC 28 January 2015) was conducted with initial conditions (ICONs) and boundary conditions (BCONs) from the National Centers for Environmental Prediction's $1^{\circ}$ grid spacing operational Global Forecast System final analyses. To represent a more realistic urban land type in the study area, fine-resolution (30 s) 20-category MODIS land-use data were used. 


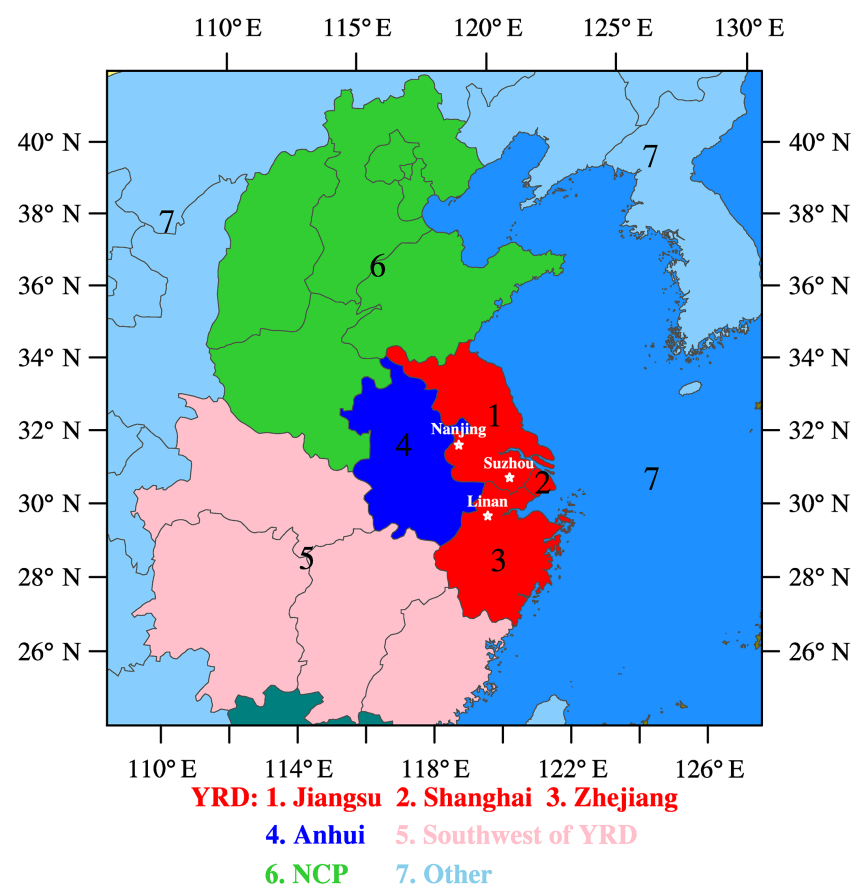

Figure 1. Modelling domain and source regions. White stars denote the locations of observation sites in Nanjing, Suzhou, and Linan.

\subsection{Configuration of air quality model}

The CMAQ (version 5.0.2) was applied to simulate gaseous and particulate air pollutants using a $10 \mathrm{~km}$ horizontal grid spacing domain that covered East China and the Korean Peninsula (Fig. 1), while the hourly meteorological field was provided by the mesoscale meteorological model WRFv3.4. A period from 10 to 28 January 2015 was selected for the simulation, with the first 9 days being the spin-up period to exclude the impacts of uncertainties in ICONs. The ICONs and BCONs for the CMAQ simulation were obtained from the modelling result of the Model for Ozone and Related Chemical Tracers (version 4), an offline global chemical transport model for the troposphere (Emmons et al., 2010). The anthropogenic emissions used in this study were provided by a mosaic Asian monthly anthropogenic emission inventory, MIX (M. Li et al., 2017), with a horizontal resolution of $0.25^{\circ} \times 0.25^{\circ}$. Biogenic emissions were generated by the Model for Emissions of Gases and Aerosols from Nature (version 2.1). The CB05 and AERO6 mechanisms were chosen for gas-phase chemistry and aerosols, respectively.

The process analysis technique introduced by Gipson (1999) was implemented in the CMAQ modelling system to determine the contributions of both physical and chemical processes to simulated species. The physical and chemical processes discussed in this study include vertical advection (ZADV), horizontal advection (HADV), vertical diffusion (VDIF), dry deposition (DDEP), cloud processes and aqueous chemistry (CLDS), and aerosol (AERO) processes.
The integrated source apportionment method (ISAM) has been implemented in CMAQ (Kwok et al., 2013). ISAM tracks contributions from ICONs, BCONs, and user-defined source regions to ambient and deposited gases and aerosol particles. Currently, ISAM supports two kinds of $\mathrm{PM}_{2.5}$ tags: a primary species tag, which tracks the primary emissions of elemental carbon, organic carbon, sulfate, nitrate, ammonium, and other trace elements (e.g. $\mathrm{Cl}, \mathrm{Na}, \mathrm{K}, \mathrm{Fe}, \mathrm{Ca}, \mathrm{Al}, \mathrm{Si}$, $\mathrm{Ti}$, and $\mathrm{Mn}$ ); and a secondary species tag, which tracks secondarily formed sulfate, nitrate, and ammonium, as well as all gaseous species associated with secondary aerosol species formations (e.g. $\mathrm{SO}_{2}, \mathrm{NO}_{2}, \mathrm{NO}, \mathrm{NO}_{3}, \mathrm{HNO}_{3}, \mathrm{HONO}, \mathrm{N}_{2} \mathrm{O}_{5}$, $\mathrm{PAN}$, and $\mathrm{NH}_{3}$ ).

\subsection{Model verification}

The model-simulated surface meteorological parameters and $\mathrm{PM}_{2.5}$ concentrations were compared with observations obtained from Nanjing, Suzhou, and Linan (Fig. 1). Figure 2 compares the surface temperature, relative humidity, wind direction, wind speed, and $\mathrm{PM}_{2.5}$ concentrations between the simulations and observations from 00:00 LT 19 January 2015 to 00:00 LT 28 January 2015. Simulations from the coupled WRF-CMAQ model appeared to effectively reproduce the variations of meteorological parameters and $\mathrm{PM}_{2.5}$ concentrations at the three observation sites.

Some statistical metrics including the correlation coefficient $(R)$, normalized mean bias (NMB), and normalized mean error (NME) were calculated to compare simulated results with observations. The NMB and NME were calculated, respectively, by Eqs. (1) and (2):

$$
\begin{aligned}
\mathrm{NMB} & =\frac{\sum_{i=1}^{N}\left(M_{i}-O_{i}\right)}{\sum_{i=1}^{N} O_{i}} \times 100 \%, \\
\mathrm{NME} & =\frac{\sum_{i=1}^{N}\left|M_{i}-O_{i}\right|}{\sum_{i=1}^{N} O_{i}} \times 100 \%,
\end{aligned}
$$

where $M_{i}$ represents the simulated value, $O_{i}$ represents the observational data, and $N$ denotes the number of data pairs. Statistical comparisons between the observed and simulated variables are shown in Table 1.

The correlation coefficients for meteorological parameters, except for wind direction and wind speed at Suzhou and Linan, were found to be around 0.90 . This discrepancy is likely because the Suzhou station is located in an urban centre, and the Linan station is located on a hill. The $10 \mathrm{~km} \times 10 \mathrm{~km}$ model grid was unable to properly represent the complicated urban canopy at Suzhou and the rolling terrain at Linan. The correlation coefficients for $\mathrm{PM}_{2.5}$ concentrations at Nanjing, Suzhou, and Linan were found to be 0.77 , 


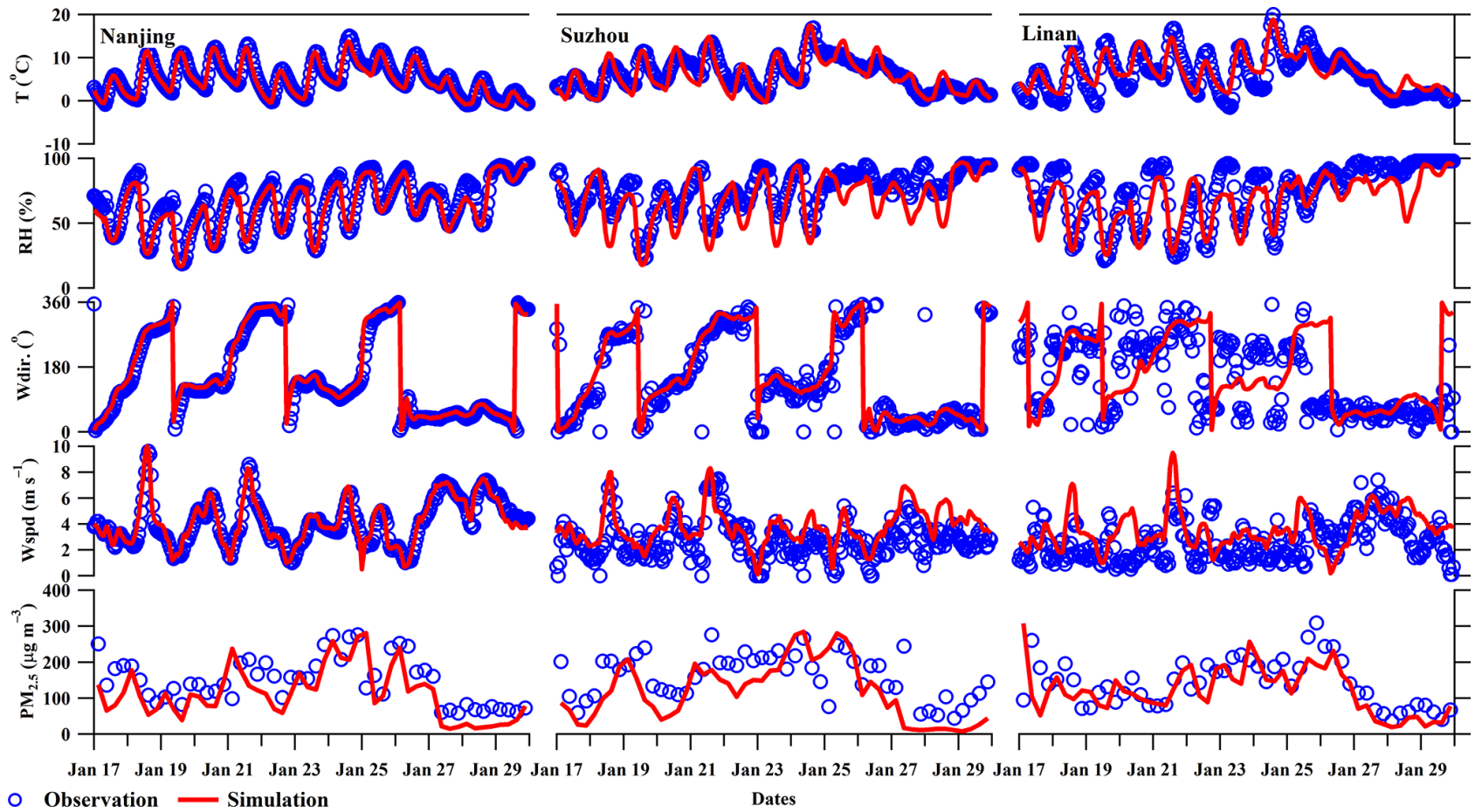

Figure 2. Observed and simulated $2 \mathrm{~m}$ air temperature $(T)$, relative humidity $(\mathrm{RH}), 10 \mathrm{~m}$ wind direction (Wdir), wind speed (Wspd), and surface $\mathrm{PM}_{2.5}$ concentrations from 00:00 LT 19 January 2015 to 00:00 LT 28 January 2015 at Nanjing, Suzhou, and Linan.

Table 1. Statistical comparisons between the observed and simulated meteorological parameters and $\mathrm{PM}_{2.5}$ concentrations at Nanjing, Suzhou, and Linan*.

\begin{tabular}{lrrr|rrr|rrr}
\hline & \multicolumn{3}{c|}{ Nanjing } & \multicolumn{3}{c|}{ Suzhou } & \multicolumn{3}{c}{ Linan } \\
\cline { 2 - 9 } & $R$ & NMB & NME & $R$ & NMB & NME & $R$ & NMB & NME \\
\hline$T$ & 0.97 & $-4.9 \%$ & $15 \%$ & 0.90 & $-4.3 \%$ & $23.6 \%$ & 0.90 & $12.9 \%$ & $30.1 \%$ \\
RH & 0.94 & $-5.1 \%$ & $7.7 \%$ & 0.84 & $-9.7 \%$ & $13.4 \%$ & 0.85 & $-9.7 \%$ & $14.8 \%$ \\
Wdir & 0.89 & $5.7 \%$ & $12.2 \%$ & 0.80 & $7.3 \%$ & $22.6 \%$ & 0.39 & $14.6 \%$ & $54.3 \%$ \\
Wspd & 0.94 & $2.0 \%$ & $11.2 \%$ & 0.68 & $37.2 \%$ & $45.4 \%$ & 0.37 & $37.4 \%$ & $61.7 \%$ \\
PM $_{2.5}$ & 0.77 & $-23.1 \%$ & $32.0 \%$ & 0.68 & $-21.9 \%$ & $34.8 \%$ & 0.74 & $-17.9 \%$ & $27.8 \%$ \\
\hline
\end{tabular}

* $R$ is correlation coefficient, NMB is normalized mean bias, NME is normalized mean error, $T$ is air temperature, $\mathrm{RH}$ is relative humidity, Wdir is wind direction, Wspd is wind speed, $\mathrm{PM}_{2.5}$ is $\mathrm{PM}_{2.5}$ concentration.

0.68 , and 0.74 , respectively. This indicates that the time series patterns of $\mathrm{PM}_{2.5}$ simulations agree well with observations. The NMB and NME for meteorological parameters were found to be relatively small, except for wind speed and wind direction at Suzhou and Linan. The model systematically underestimated $\mathrm{PM}_{2.5}$ concentrations by about $20 \%$ for all three stations. This can probably be attributed to the coarse model grid size and lower emission resolution. The NME for $\mathrm{PM}_{2.5}$ at all three stations was found to be below $35 \%$, indicating that model performance was acceptable.

\section{Episode description}

The YRD region was suffering from particle pollution in January 2015. The field experiment was carried out from 00:00 LT 19 January 2015 to 00:00 LT 28 January 2015 at Nanjing, Suzhou, and Linan (Fig. 1). The Nanjing observation site is located in a suburban area, the Suzhou station is located in an urban area, and the Linan station represents the regional background site. Observations revealed that 9day mean $\mathrm{PM}_{2.5}$ concentrations reached $100 \mu \mathrm{g} \mathrm{m}^{-3}$ at the Nanjing and Suzhou sites. In some high-pollution episodes, $\mathrm{PM}_{2.5}$ concentrations reached as high as $300 \mu \mathrm{g} \mathrm{m}^{-3}$ (Fig. 3).

A short-term burst of $\mathrm{PM}_{2.5}$ pollution accompanied by strong north-west winds successively appeared in Nanjing, 


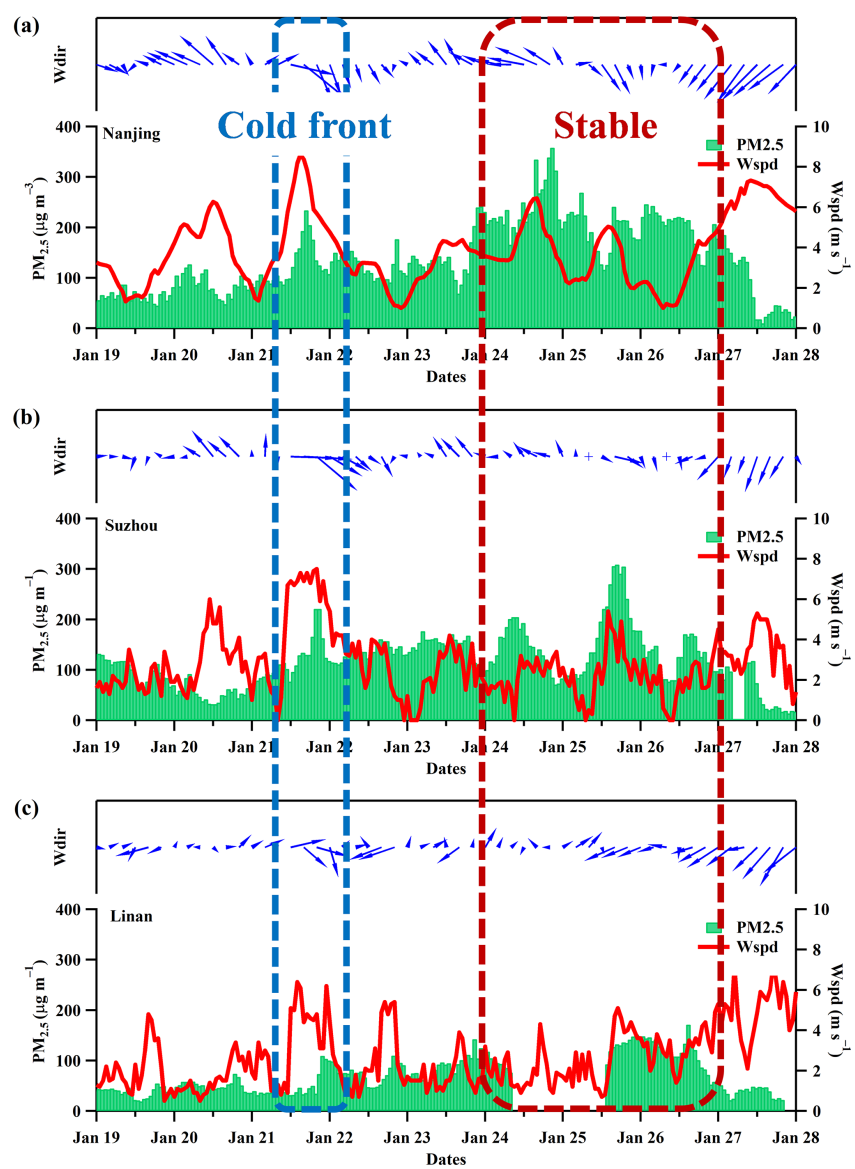

Figure 3. $\mathrm{PM}_{2.5}$ concentrations (green bars), wind speeds (Wspd, red lines), and wind directions (Wdir, vectors) at (a) Nanjing, (b) Suzhou, and (c) Linan.

Suzhou, and Linan between 12:00 LT 21 January 2015 and 04:00 LT 22 January 2015 (Fig. 3). The peaks of $\mathrm{PM}_{2.5}$ concentrations reached Nanjing, Suzhou, and Linan at 16:00, 19:00, and 21:00 LT, respectively, with a $5 \mathrm{~h}$ delay from Nanjing to Linan. This process reveals that a strong northwesterly flow brought a polluted air mass across the YRD. Synoptic maps show dense isobars at the head of the cold front, which appeared over the north (upstream) of the YRD at 08:00 LT 21 January 2015 (Fig. 4a). At that moment, a south-westerly wind prevailed in the YRD. Twelve hours later, the cold front moved to the East China Sea (downstream of YRD; Fig. 4b). Meanwhile, the wind direction over the YRD shifted to the north-west, which was favourable for the horizontal transport of air pollutants from the upstream area to the YRD.

In order to validate whether this finding was just a special case or not, further investigations were conducted using three months (from December 2014 to February 2015) of $\mathrm{PM}_{2.5}$ and meteorological observation data. The result showed that at least 13 cold frontal processes transported atmospheric pollutants from the NCP to YRD in the three months (see
Fig. S1 in the Supplement). That means long-range transport of air pollutants by cold frontal passage may be an important cause of air pollution over YRD in wintertime; however, we did not notice it before. Note that the cold front generally deteriorates air quality over the YRD in a short time period, but it will finally clean the atmosphere.

After the cold frontal episode, YRD experienced a uniform pressure field for about 3 days (Fig. 4c, d), creating conditions that were unfavourable for the horizontal transport and vertical mixing of atmospheric pollutants (Zhu et al., 2010). Aerosol particles gradually accumulated over the YRD under this stable atmosphere. In order to exclude the impact of the cold front, this study designated the stable period from 24 to 27 January 2015, when the wind speed was relatively low but $\mathrm{PM}_{2.5}$ concentrations were extremely high (Fig. 3), indicating that the pollution likely originated locally. On 27 January 2015, a strong cold front intruded into the YRD accompanied by precipitation, resulting in the significant removal of $\mathrm{PM}_{2.5}$.

\section{Results and discussion}

Observations revealed that the cold front pushed polluted air masses over the NCP to YRD, which increased $\mathrm{PM}_{2.5}$ concentration over YRD on 21 January. This finding is reproduced by the well-evaluated WRF model. Based on this finding, we considered the formation processes and source contributions of $\mathrm{PM}_{2.5}$ pollution over the YRD during the cold frontal passage and the subsequent stable weather conditions.

\subsection{Formation processes of high $\mathbf{P M}_{2.5}$ during cold frontal passage}

A strong wind accompanied by high $\mathrm{PM}_{2.5}$ concentrations is favourable for the long-range transport of aerosols. Timeaveraged $\mathrm{PM}_{2.5}$ concentrations and fluxes at the surface and $1.0 \mathrm{~km}$ altitude during the cold frontal passage are shown in Fig. 5. High $\mathrm{PM}_{2.5}$ concentrations $\left(>100 \mu \mathrm{g} \mathrm{m}^{-3}\right.$ ) and high wind speeds can be observed both at the surface (Fig. 5a) and at $1.0 \mathrm{~km}$ (Fig. 5b), resulting in strong $\mathrm{PM}_{2.5}$ fluxes from polluted upstream regions to downstream regions. Mean $\mathrm{PM}_{2.5}$ fluxes at the surface and at $1.0 \mathrm{~km}$ were 619 and $1072 \mu \mathrm{g} \mathrm{m}^{-2} \mathrm{~s}^{-1}$, respectively. $\mathrm{PM}_{2.5}$ fluxes were stronger at $1.0 \mathrm{~km}$ than at the surface because the wind speed was higher, while the $\mathrm{PM}_{2.5}$ concentrations were comparable to those at surface levels. We can conclude that high altitudes are important aerosol transport pathways during cold frontal passage; they are probably more important than surface transport pathways.

Figure 6 shows a vertical cross section of $\mathrm{PM}_{2.5}$ concentration, $\mathrm{PM}_{2.5}$ flux, and equivalent potential temperature (EPT) along the aerosol transport pathway (indicated by the dashed red line in Fig. 5b) during the cold frontal passage through the YRD from 12:00 LT 21 January to 04:00 LT 22 January. 

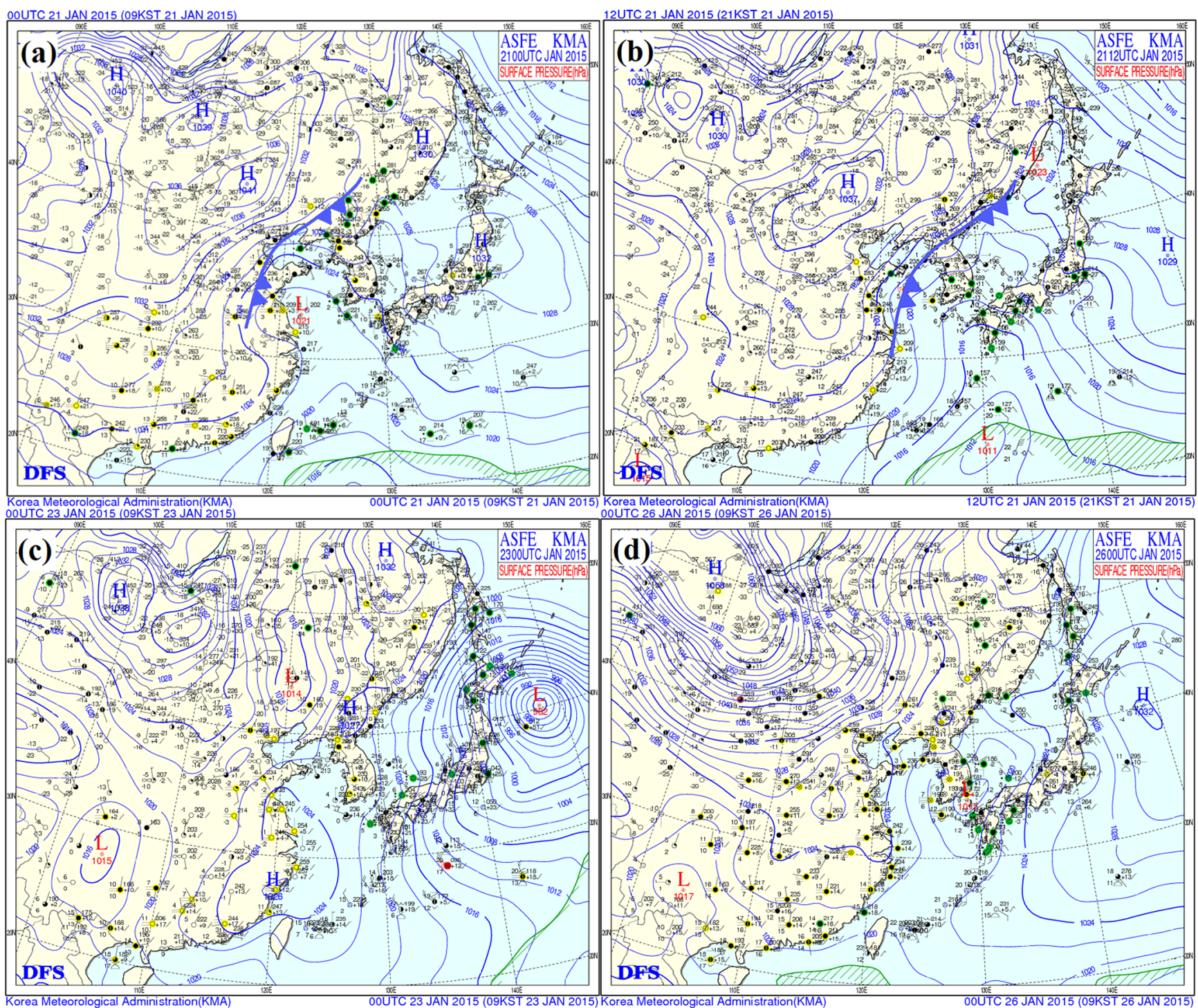

Figure 4. Surface weather patterns over eastern Asia at (a) 08:00 LT 21 January, (b) 20:00 LT 21 January, (c) 08:00 LT 23 January, and (d) 08:00 LT 26 January.

An obvious cold front can be identified over the northern YRD from the densely spaced EPT contours near-surface and vertical wind shear (Fig. 6a). The EPT contours reveal a stable layer over the YRD with isentropic tilt toward the cold air and parallel to the cold front. Wind vectors show clear downward (upward) movements in the north (south) of the cold front (red lines in Fig. 6a and b).

At noon (12:00 LT) on 21 January, the cold front reached the northern boundary of the YRD accompanied by high $\mathrm{PM}_{2.5}$ concentrations $\left(>100 \mu \mathrm{g} \mathrm{m}^{-3}\right.$ ) and strong $\mathrm{PM}_{2.5}$ fluxes (800-1600 $\mu \mathrm{g} \mathrm{m}^{-2} \mathrm{~s}^{-1}$; Fig. 6a). At the southern end of the cold front, the vertical extent of the high $\mathrm{PM}_{2.5}$ concentrations $\left(100 \mu \mathrm{g} \mathrm{m}^{-3}\right)$ reached $2.0 \mathrm{~km}$, significantly higher than the boundary layer height (around $0.6-0.8 \mathrm{~km}$, not shown in Fig. 6a). Therefore, the vertical transport of
$\mathrm{PM}_{2.5}$ is inferred to be caused by systematic prefrontal upward movements rather than boundary layer turbulent mixing. Surface $\mathrm{PM}_{2.5}$ concentrations exceeded $100 \mu \mathrm{g} \mathrm{m}{ }^{-3}$ over the YRD before the cold front's arrival. When the cold front moved into the YRD, it forced the warm and polluted YRD air mass ahead of the frontal zone up along the frontal boundary, lifting $\mathrm{PM}_{2.5}$ into the upper air (Ding et al., 2009). Liu (2003) suggested that this kind of frontal lifting promotes the transport of pollution to the free troposphere.

In the afternoon (16:00 LT) of 21 January, the cold front intruded into the YRD (Fig. 6b). A deep neutral condition (see Fig. S2) appeared over the YRD because of the strong wind. The high $\mathrm{PM}_{2.5}$ concentration zone moved south alongside the cold front. Aerosols from the NCP were transported to 

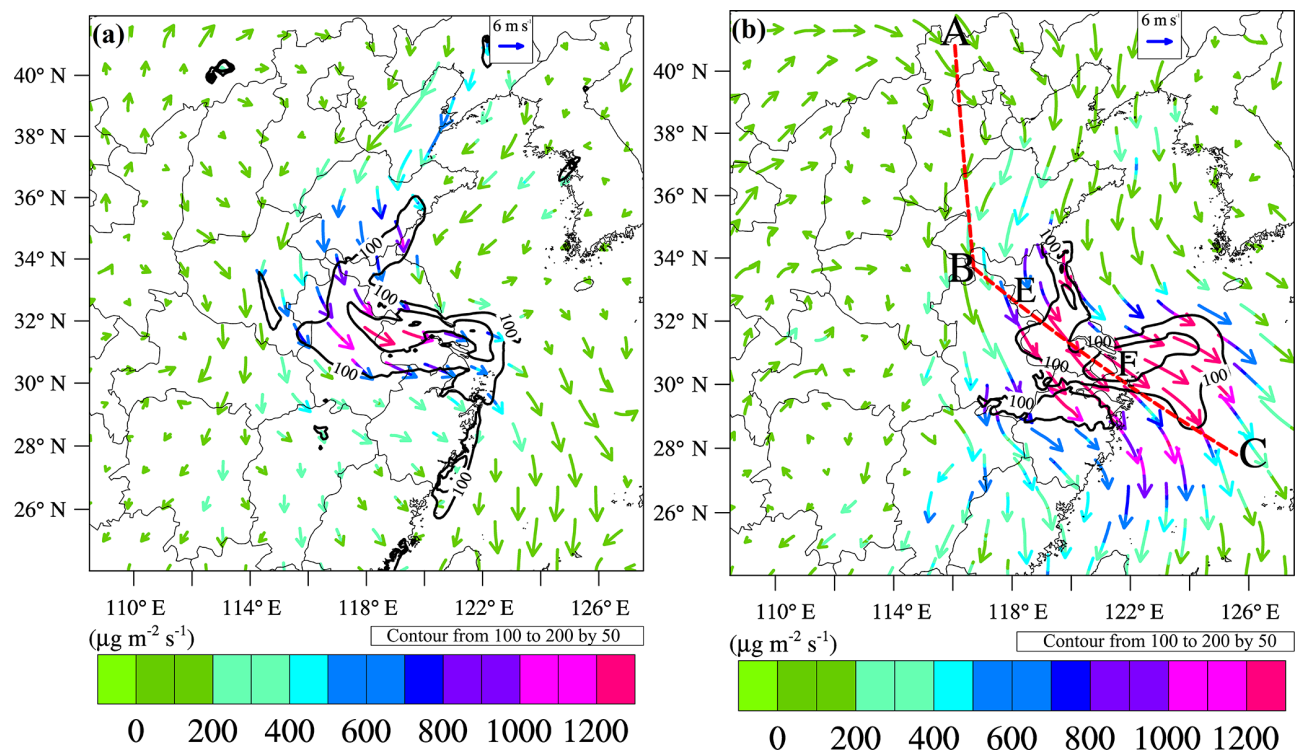

Figure 5. Mean wind vectors (arrow), $\mathrm{PM}_{2.5}$ flux (coloured arrow), and mass concentration (black contours) at (a) the surface and (b) $1.0 \mathrm{~km}$ altitude from 12:00 LT 21 January 2015 to 04:00 LT 22 January 2015. The dashed red line (A-B-C) in Fig. 5b denotes the location of the vertical cross section shown in Fig. 6. Points E and F indicate the YRD locations shown in Fig. 6.
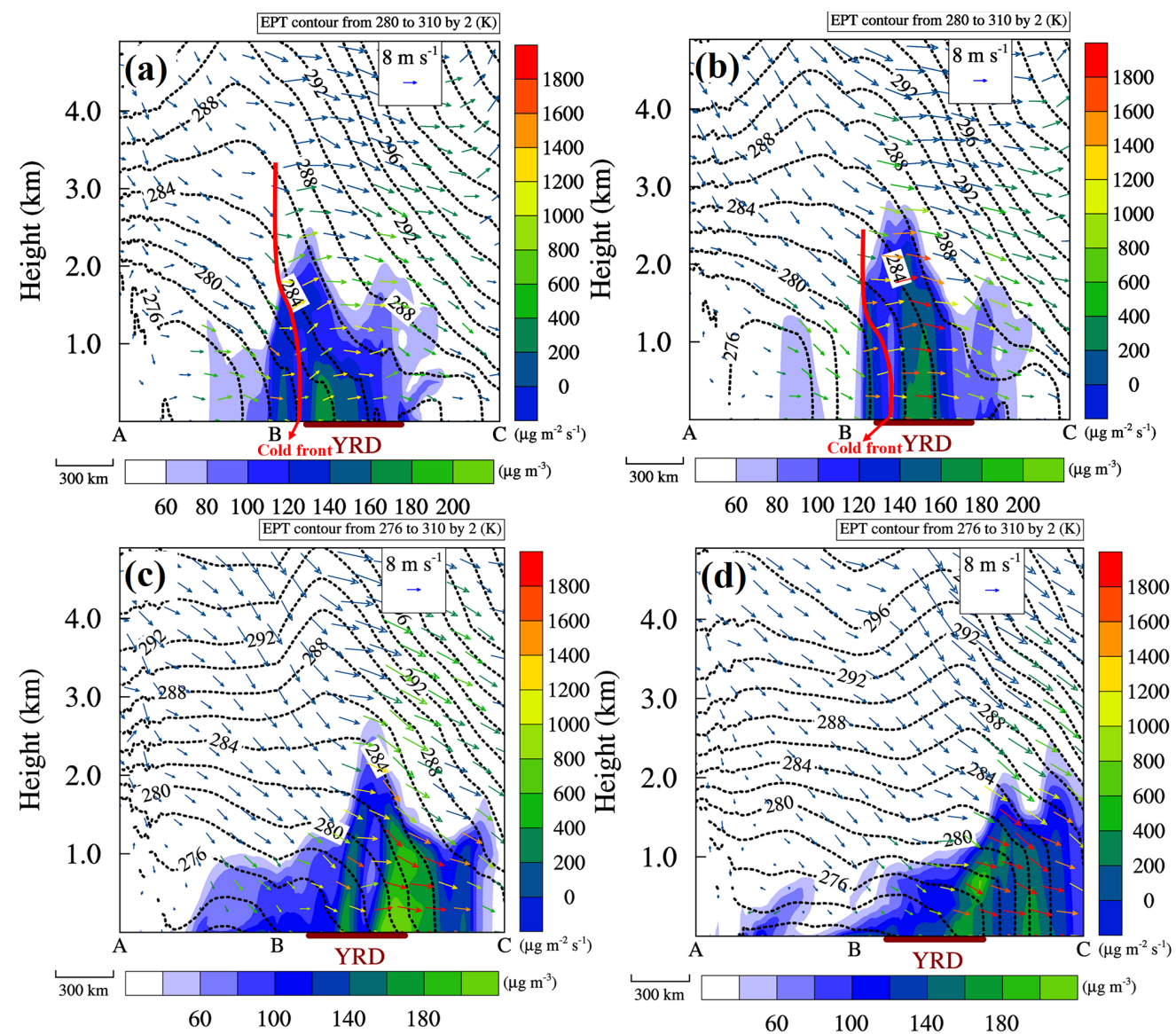

Figure 6. Vertical cross sections of $\mathrm{PM}_{2.5}$ concentration (colour-filled contours), and equivalent potential temperature (EPT, dashed black lines), in-plane wind vectors (arrow) where the vertical speed is multiplied by 100, and $\mathrm{PM}_{2.5}$ flux (arrow colour), at (a) 12:00 LT 21 January, (b) 16:00 LT 21 January, (c) 22:00 LT 21 January, and (d) 04:00 LT 22 January. The thicker red lines in panels (a) and (b) denote the locations of the cold front. 

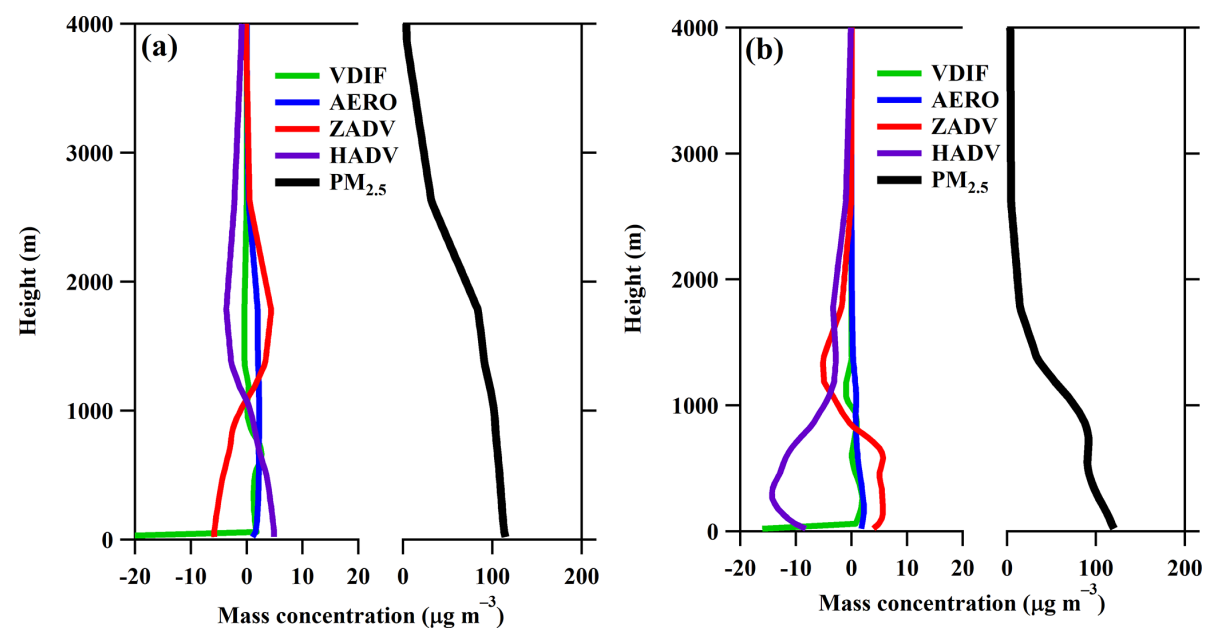

Figure 7. Vertical profiles of $\mathrm{PM}_{2.5}$ concentrations and the contributions of physical/chemical processes over the centre of the YRD (from 30 to $33^{\circ} \mathrm{N}$ ) to $\mathrm{PM}_{2.5}$ concentrations (a) at the beginning and (b) at the end of the cold frontal period.

the YRD by strong north-westerly frontal airflow, and hence increased aerosol concentrations and fluxes over the YRD.

At the end of the cold frontal period (Fig. 6c, d), when the frontal zone moved downstream of the YRD, the YRD was under a high-pressure system that resulted in divergence (e.g. the vertical $\mathrm{PM}_{2.5}$ flux at $1.0 \mathrm{~km}$ was about $-0.9 \mu \mathrm{g} \mathrm{m}^{-2} \mathrm{~s}^{-1}$, and at $0.5 \mathrm{~km}$ was about $-0.5 \mu \mathrm{g} \mathrm{m}^{-2} \mathrm{~s}^{-1}$ ). Synoptic subsidence behind the frontal zone would suppress the upward transport of $\mathrm{PM}_{2.5}$, increasing the surface particle concentration (Mari, 2004). Up until the next morning (04:00 LT 22 January), high $\mathrm{PM}_{2.5}$ concentrations were primarily restricted to below $1.0 \mathrm{~km}$ over the YRD (Fig. 6d), because the downward motion behind the frontal zone trapped air pollutants in the boundary layer. Additionally, an extremely strong southward $\mathrm{PM}_{2.5}$ flux $\left(>1800 \mu \mathrm{g} \mathrm{m}^{-2} \mathrm{~s}^{-1}\right)$ can be identified over the YRD, indicating the transport pathway of $\mathrm{PM}_{2.5}$ (Fig. 6c). The high concentration of $\mathrm{PM}_{2.5}$ that appeared over both the YRD and its downstream regions was probably due to the mixing of locally emitted particles with those brought by the cold front from the NCP.

A process analysis technique was introduced to evaluate the effects of physical and chemical processes on aerosol vertical distributions over the YRD. Figure 7 shows the profiles of the averaged $\mathrm{PM}_{2.5}$ concentrations and the contributions of VDIF, AERO, ZADV, and HADV processes over the centre of the YRD (from 30 to $33^{\circ} \mathrm{N}$, including Shanghai, south of Jiangsu, and north of Zhejiang, since the whole YRD is larger than the frontal zone) to $\mathrm{PM}_{2.5}$ concentrations during the cold frontal passage. At the beginning of the cold front period (12:00 to 16:00 LT 21 January), the centre of the YRD was located ahead of the frontal zone, and the contributions of vertical advection processes to $\mathrm{PM}_{2.5}$ concentrations were negative (decreased aerosol concentrations) below $1.0 \mathrm{~km}$, but positive (increased aerosol concentrations) between 1.0 and $2.5 \mathrm{~km}$ (Fig. 7a). This supports the previous conclusion that vertical motions ahead of the frontal zone lifted particles from the boundary layer to the free troposphere.

The horizontal advection process increased $\mathrm{PM}_{2.5}$ concentrations below $1.0 \mathrm{~km}$ but decreased $\mathrm{PM}_{2.5}$ concentrations above $1.0 \mathrm{~km}$. Through the horizontal advection process, the cold air mass brought aerosols from the NCP to the YRD, increasing the surface aerosol concentration over the YRD. The negative contribution of horizontal advection above $1.0 \mathrm{~km}$ was probably due to aerosol concentrations being increased by strong prefrontal lifting that transported aerosols from the surface to the free troposphere, thus strengthening the outflow of free-tropospheric aerosols from the YRD. The vertical diffusion process has a relatively small effect on aerosol vertical distributions except for in the first layer, where most of the emissions exist. Vertical aerosol concentrations were slightly increased through secondary aerosol formation.

The profiles of averaged $\mathrm{PM}_{2.5}$ concentrations and the contributions of physical and chemical processes to $\mathrm{PM}_{2.5}$ concentrations over the centre of the YRD at the end of the cold frontal period (22:00 LT 21 January to 04:00 LT 22 January) are shown in Fig. 7b. The vertical advection process made positive contributions to $\mathrm{PM}_{2.5}$ concentrations in the lower atmosphere but negative contributions in the upper atmosphere - the opposite of the result obtained at the beginning of cold frontal passage. This result indicates that divergence behind the frontal zone (Fig. 6c, d) transports particles from the lower free troposphere to the boundary layer. The contributions of the horizontal advection process were negative between the surface and the free troposphere, implying a net horizontal outflow of aerosols from the YRD. At this time, the region upstream of the YRD was cleaner than the YRD itself. 

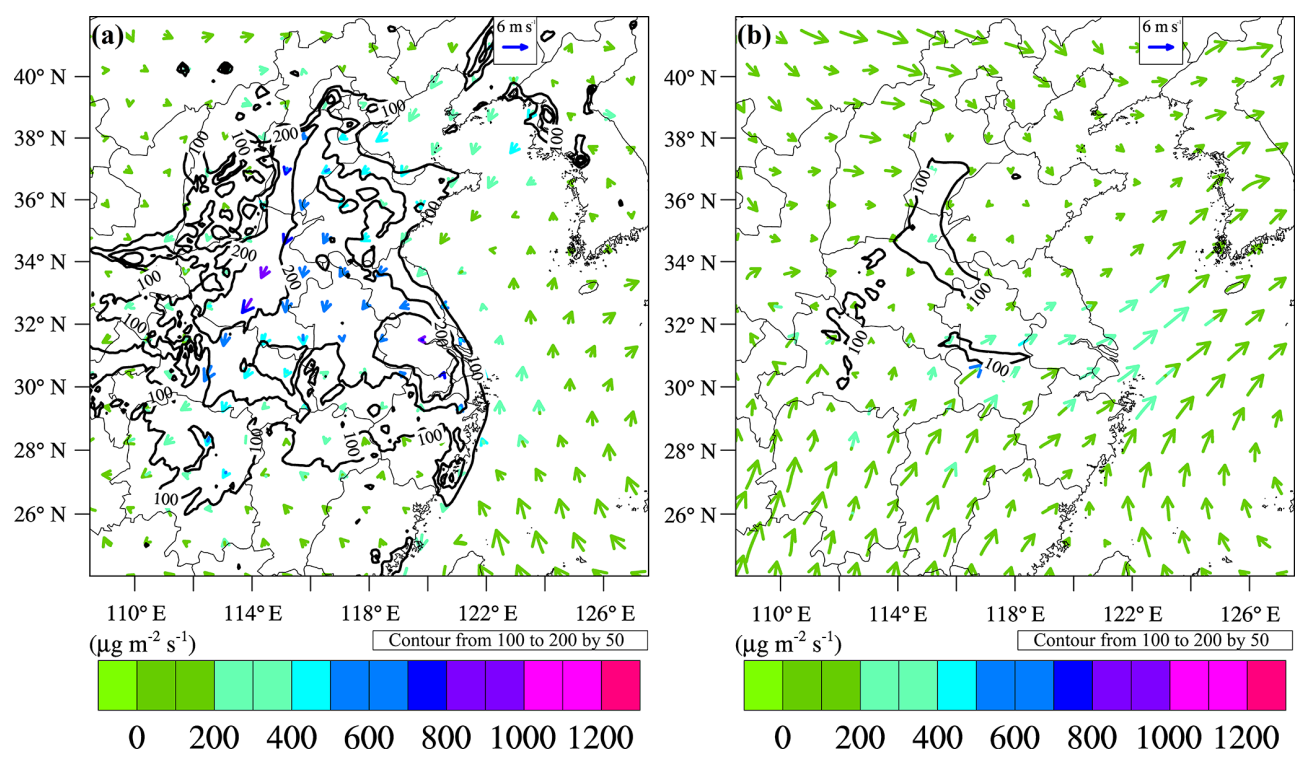

Figure 8. Averaged $\mathrm{PM}_{2.5}$ flux (coloured arrows) and mass concentrations (black contour) at (a) the surface and (b) $1.0 \mathrm{~km}$ altitude from 00:00 LT 24 January 2015 to 00:00 LT 27 January 2015.

\subsection{Formation processes of high $\mathrm{PM}_{2.5}$ concentrations under stable weather}

After the cold frontal episode, aerosol particles started to accumulate under a stable atmosphere that resulted in high $\mathrm{PM}_{2.5}$ concentrations in the near-surface layer over east China (Fig. 8a). In the centre of the YRD, the mean $\mathrm{PM}_{2.5}$ concentration was more than $200 \mathrm{\mu g} \mathrm{m}^{-3}$ higher than that of the cold frontal period, but the $\mathrm{PM}_{2.5}$ concentrations at $1.0 \mathrm{~km}$ (Fig. 8b) were significantly lower. The $\mathrm{PM}_{2.5}$ fluxes in the stable atmosphere were lower than those in the cold frontal passage at both the surface and $1.0 \mathrm{~km}$, reflecting the lower mean wind velocity under stable weather. This indicates that atmospheric conditions were not favourable for the horizontal transport of $\mathrm{PM}_{2.5}$.

The averaged $\mathrm{PM}_{2.5}$ profile over the YRD shows significant vertical gradients under stable weather (Fig. 9). The process analysis showed that the vertical advection process transported $\mathrm{PM}_{2.5}$ from the surface to the upper air. However, this vertical transport only reached $1.0 \mathrm{~km}$ altitude - much lower than it did during the cold frontal passage $(\sim 2.0 \mathrm{~km})$. Horizontal advection shows a small negative contribution to $\mathrm{PM}_{2.5}$ concentrations over the YRD from the surface to $1.0 \mathrm{~km}$. This indicates that there was a weak outflow of $\mathrm{PM}_{2.5}$ from the YRD to its surroundings, because the YRD is an important aerosol source region. Vertical diffusion mixed $\mathrm{PM}_{2.5}$ between the surface and the upper air, but its contribution to $\mathrm{PM}_{2.5}$ was relatively small. Secondary aerosol formation slightly increased the aerosol concentration from the surface to $1.0 \mathrm{~km}$.

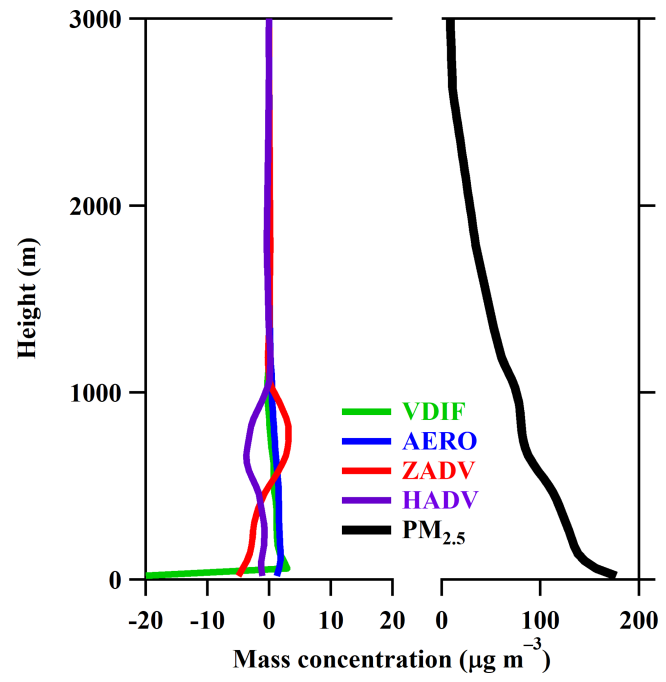

Figure 9. Vertical profiles of $\mathrm{PM}_{2.5}$ concentrations and the contributions of physical/chemical processes to $\mathrm{PM}_{2.5}$ concentrations during the period of stable weather.

\subsection{Contributions of $\mathrm{PM}_{2.5}$ from source regions to the YRD}

Anthropogenic emissions are the fundamental source of $\mathrm{PM}_{2.5}$. Knowing the source regions of aerosols and their contributions to the YRD is critical in controlling $\mathrm{PM}_{2.5}$ pollution. Our results revealed a significant transport of aerosol particles from the NCP to the YRD during the cold frontal passage and a remarkable local $\mathrm{PM}_{2.5}$ contribution during stable weather conditions. Based on these results, we derived 


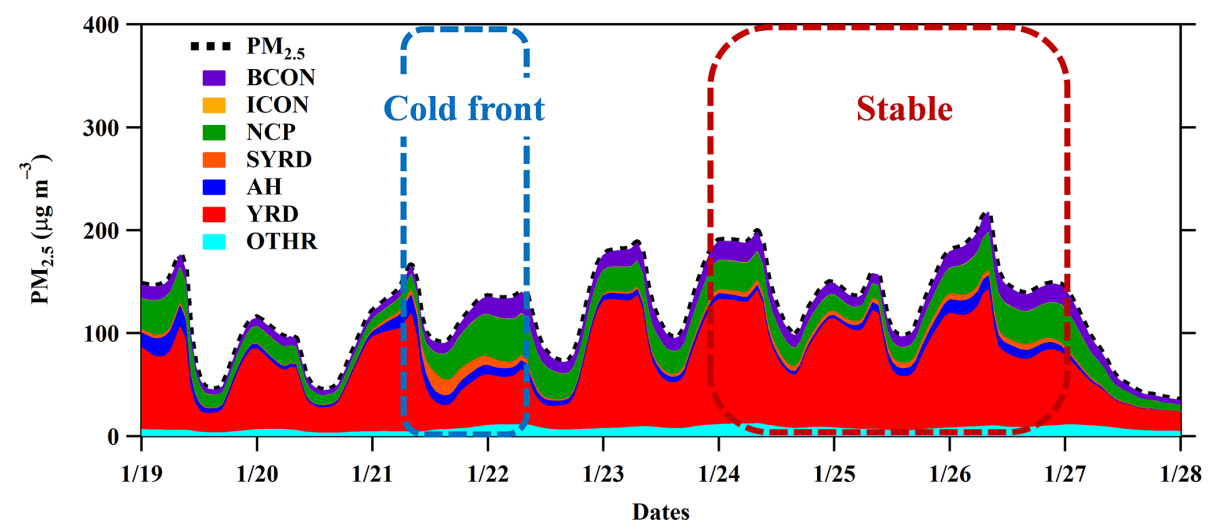

Figure 10. Time series of $\mathrm{PM}_{2.5}$ concentrations and contributions of source regions to the $\mathrm{PM}_{2.5}$ concentrations over the Yangtze River Delta (YRD) from 19 to 28 January 2015. SYRD is south-west of YRD, AH is Anhui, and OTHR is other.

the contributions of $\mathrm{PM}_{2.5}$ from source regions to the YRD using ISAM, which was incorporated in the CMAQ model.

Mass contributions from each of the geographical source regions, BCONs, and ICONs to $\mathrm{PM}_{2.5}$ concentrations over the YRD from 19 to 28 January 2015 are shown in Fig. 10. The YRD is a quickly developing and densely populated region where anthropogenic activities such as industrial production, vehicle usage, power plant operation, and residential activities release huge volumes of atmospheric pollutants. Therefore, in the YRD, the most significant source of $\mathrm{PM}_{2.5}$ is local emissions (Fig. 10). The NCP is another heavily polluted region in east China (Cao et al., 2015; Chen and Wang, 2015; J. Li et al., 2017), located adjacent to YRD to the south. On 21 January, a cold front brought polluted air mass from the NCP to the YRD resulting in a high contribution of $\mathrm{PM}_{2.5}$. $\mathrm{PM}_{2.5}$ from regions outside of the modelling domain (BCONs) also impacted on the $\mathrm{PM}_{2.5}$ concentration over the YRD through long-range transport. However, contributions from other source regions were relatively small.

Mean contributions from each source region from 19 to 28 January 2015 are shown in Fig. 11a. Local contributions (from the YRD itself) accounted for $56.5 \%$ of the $\mathrm{PM}_{2.5}$ concentration, in which Jiangsu, Shanghai, and Zhejiang accounted for $32.5 \%, 3.5 \%$, and $20.5 \%$, respectively. $\mathrm{PM}_{2.5}$ from the NCP and BCONs contributed $18.5 \%$ and $10.5 \%$, respectively. The YRD, NCP, and BCONs contributed $85.5 \%$ in total. During the cold frontal passage, a strong north-west wind prevailed over the YRD; locally originated aerosols only accounted for $35 \%$ of the $\mathrm{PM}_{2.5}$ contribution, with Jiangsu, Shanghai, and Zhejiang accounting for $22 \%, 2 \%$, and $11 \%$, respectively (Fig. 11b). These contributions are much lower than those in the total average because the strong wind in the cold frontal period was unfavourable for the accumulation of locally emitted pollutants. $\mathrm{PM}_{2.5}$ from the NCP contributed $29 \%$ to the $\mathrm{PM}_{2.5}$ concentrations over YRD, a significantly higher amount than in the average contribution. Contributions from other geographical source regions were also increased during the cold frontal passage because of the long-range transport of aerosol. In general, the cold front decreased local contributions in the YRD, but increased long-range transport contributions from the NCP region.

Under stable weather conditions, local contributions $(61.5 \%)$ were increased, especially for Zhejiang province (Fig. 11c). Lower wind speeds during the stable period were unfavourable for the transport of pollutants, resulting in high $\mathrm{PM}_{2.5}$ concentrations and significant local contributions. NCP contributed $14.5 \%$ to $\mathrm{PM}_{2.5}$ concentrations over the YRD, accounting for only half that in the cold frontal period. In general, $\mathrm{PM}_{2.5}$ contributions in the stable period were similar to those in the total average, but with higher local contributions and lower NCP contributions.

\section{Conclusions}

Cold fronts are favourable to the outflow of $\mathrm{PM}_{2.5}$ in the $\mathrm{BTH}$ region, decreasing aerosol concentrations as soon as they reach the area. However, in the YRD, cold fronts remove local aerosol particles and can also introduce upstream air pollutants. Understanding the processes of $\mathrm{PM}_{2.5}$ transport during the cold frontal passage is of great significance for the understanding of haze formation mechanisms over the YRD in wintertime. In this study, the coupled WRF-CMAQ model was employed to investigate the processes and mechanisms of $\mathrm{PM}_{2.5}$ pollution over the YRD under a cold frontal intrusion period and subsequent stable weather conditions in January 2015.

Observations at three sites show that high $\mathrm{PM}_{2.5}$ concentrations and strong north-westerly winds appeared simultaneously as the locations of the peak $\mathrm{PM}_{2.5}$ concentration moved from north to south, indicating that the cold front transported aerosol particles across the YRD. At the beginning of the cold frontal passage, when the cold front first reached the YRD, it forced the warm and polluted YRD air mass ahead of the frontal zone to move up along the frontal boundary, 
(a)

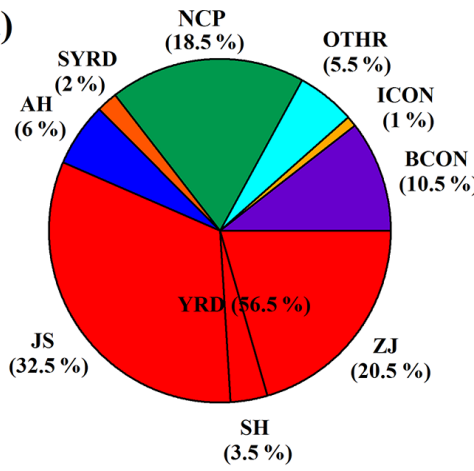

(b)

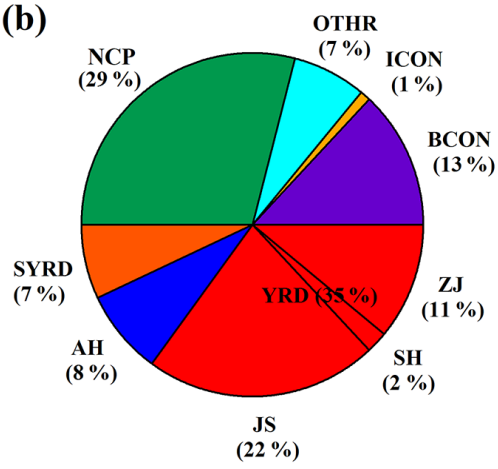

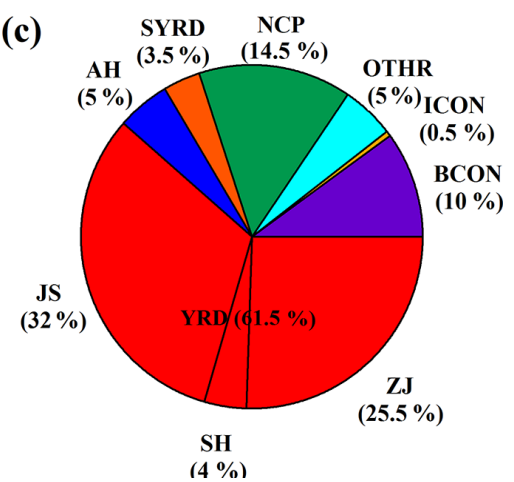

Figure 11. Contribution rate of each source region to $\mathrm{PM}_{2.5}$ over the Yangtze River Delta (YRD) during (a) the whole simulation period, (b) the cold frontal passage, and (c) under the stable weather conditions. JS is Jiangsu, SH is Shanghai, and ZJ is Zhejiang.

lifting $\mathrm{PM}_{2.5}$ into the free troposphere. As the cold front intruded deep into the YRD, aerosols from upstream areas (NCP) were transported to the YRD by strong north-westerly frontal airflow. At the end of the cold frontal period, when the frontal zone had moved downstream of YRD (East China Sea), high pressure took control over the YRD, resulting in divergence over the region. The synoptic subsidence motions trapped $\mathrm{PM}_{2.5}$ in the boundary layer. The atmospheric stratification became stable after the cold front from 24 to 27 January 2015. Aerosol particles over the YRD then began to reaccumulate until the next cold front.

The contributions of $\mathrm{PM}_{2.5}$ from each of the defined source regions were calculated by ISAM. For the entire 9-day simulation (19-28 January), $\mathrm{PM}_{2.5}$ contributions from the local area (YRD), NCP, and BCONs accounted for $56.5 \%$, $18.5 \%$, and $10.5 \%$, respectively. During the cold frontal passage (12:00 LT 21 January to 04:00 LT 22 January), local $\mathrm{PM}_{2.5}$ contributions decreased to $35 \%$, while contributions from the NCP increased to $29 \%$. During the stable weather conditions (00:00 LT 24 January to 00:00 LT 27 January), local $\mathrm{PM}_{2.5}$ contributions increased to $61.5 \%$ while NCP contributions decreased to $14.5 \%$. This result indicates that cold fronts intensify the long-range transport of air pollutants in the NCP to the YRD.

Data availability. All observations and model outputs used in this study are available. Readers can access the data directly or by contacting Bin Zhu via binzhu@ nuist.edu.cn.

Supplement. The supplement related to this article is available online at: https://doi.org/10.5194/acp-19-3673-2019-supplement.

Author contributions. HK was responsible for paper writing, model simulation, and data analysis. BZ proposed the idea and did the paper revision. JG performed model result processing and plotting. YH performed observation data processing and plotting. HW performed observation data collection. JS was responsible for weather map analysis. CP provided scripts for data processing. TZ contributed to the paper revision and language editing. BY provided meteorological observations at Linan.

Competing interests. The authors declare that they have no conflict of interest.

Special issue statement. This article is part of the special issue "Regional transport and transformation of air pollution in eastern China". It is not associated with a conference.

Acknowledgements. This work was supported by the National Natural Science Foundation of China (grant nos. 91544229, 41605091, and 41605096), the National Key Research and Development Program (grant no. 2016YFA0602003), The Startup Foundation for Introducing Talent of NUIST (grant no. 2243141501035), the Hangzhou Scientific Research Project in Agriculture and Social Development (grant no. 20170533B16), SUSTC Presidential Postdoctoral Fellowship, and the open fund by the Key Laboratory for Aerosol-Cloud-Precipitation of CMA-NUIST (grant no. KDW1701). We acknowledge the free use of MIX emission from Tsinghua University.

Edited by: Tong Zhu

Reviewed by: two anonymous referees

\section{References}

Cao, Z., Sheng, L., Liu, Q., Yao, X., and Wang, W.: Interannual increase of regional haze-fog in North China Plain in summer by intensified easterly winds and orographic forcing, Atmos. Environ., 122, 154-162, https://doi.org/10.1016/j.atmosenv.2015.09.042, 2015.

Chen, F., Kusaka, H., Tewari, M., Bao, J.-W., and Hirakuchi, H.: Utilizing the coupled WRF/LSM/urban modeling system with detailed urban classification to simulate the urban heat island phenomena over the greater Houston area, in: 5th Conference 
On Urban Environment, Vancouver, BC Canada, 23-27 August 2004, available at: http://ams.confex.com/ams/pdfpapers/79765. pdf (last access: 18 March 2019), 2004.

Chen, H. and Wang, H.: Haze Days in North China and the associated atmospheric circulations based on daily visibility data from 1960 to 2012, J. Geophys. Res.-Atmos., 120, 5895-5909, https://doi.org/10.1002/2015jd023225, 2015.

Ding, A., Wang, T., Xue, L., Gao, J., Stohl, A., Lei, H., Jin, D., Ren, Y., Wang, X., Wei, X., Qi, Y., Liu, J., and Zhang, X.: Transport of north China air pollution by midlatitude cyclones: Case study of aircraft measurements in summer 2007, J. Geophys. Res., 114, D08304, https://doi.org/10.1029/2008jd011023, 2009.

Emmons, L. K., Walters, S., Hess, P. G., Lamarque, J.-F., Pfister, G. G., Fillmore, D., Granier, C., Guenther, A., Kinnison, D., Laepple, T., Orlando, J., Tie, X., Tyndall, G., Wiedinmyer, C., Baughcum, S. L., and Kloster, S.: Description and evaluation of the Model for Ozone and Related chemical Tracers, version 4 (MOZART-4), Geosci. Model Dev., 3, 43-67, https://doi.org/10.5194/gmd-3-43-2010, 2010.

Gao, J., Tian, H., Cheng, K., Lu, L., Zheng, M., Wang, S., Hao, J., Wang, K., Hua, S., Zhu, C., and Wang, Y.: The variation of chemical characteristics of $\mathrm{PM}_{2.5}$ and $\mathrm{PM}_{10}$ and formation causes during two haze pollution events in urban Beijing, China, Atmos. Environ., 107, 1-8, https://doi.org/10.1016/j.atmosenv.2015.02.022, 2015.

Gao, M., Carmichael, G. R., Wang, Y., Saide, P. E., Yu, M., Xin, J., Liu, Z., and Wang, Z.: Modeling study of the 2010 regional haze event in the North China Plain, Atmos. Chem. Phys., 16, 1673-1691, https://doi.org/10.5194/acp-16-1673-2016, 2016.

Gao, M., Saide, P., Xin, J., Wang, Y., Liu, Z., Wang, Y., Wang, Z., Pagowski, M., Guttikunda, S., and Carmichael, G.: Estimates of Health Impacts and Radiative Forcing in Winter Haze in Eastern China through Constraints of Surface $\mathrm{PM}_{2.5}$ Predictions, Environ. Sci. Technol., 51, 2178-2185, 2017.

Gipson, G. L.: Science Algorithms of the EPA Models-3 Community Multiscale Air Quality (CMAQ) Modeling System: Process analysis, EPA/600/R-99/030, U.S. EPA, available at: https://www.cmascenter.org/cmaq/science_documentation/pdf/ ch16.pdf (last access: 18 March 2019), 1999.

Guo, S., Hu, M., Zamora, M. L., Peng, J., Shang, D., Zheng, J., Du, Z., Wu, Z., Shao, M., Zeng, L., Molina, M. J., and Zhang, R.: Elucidating severe urban haze formation in China, P. Nati. Acad. Sci. USA, 111, 17373-17378, https://doi.org/10.1073/pnas.1419604111, 2014.

Han, R., Wang, S., Shen, W., Wang, J., Wu, K., Ren, Z., and Feng, M.: Spatial and temporal variation of haze in China from 1961 to 2012, J. Environ. Sci., 46, 134-146, https://doi.org/10.1016/j.jes.2015.12.033, 2016.

Huang, R.-J., Zhang, Y., Bozzetti, C., Ho, K.-F., Cao, J.-J., Han, Y., Daellenbach, K. R., Slowik, J. G., Platt, S. M., Canonaco, F., Zotter, P., Wolf, R., Pieber, S. M., Bruns, E. A., Crippa, M., Ciarelli, G., Piazzalunga, A., Schwikowski, M., Abbaszade, G., SchnelleKreis, J., Zimmermann, R., An, Z., Szidat, S., Baltensperger, U., Haddad, I. E., and Prévôt, A. S. H.: High secondary aerosol contribution to particulate pollution during haze events in China, Nature, 514, 218-222, https://doi.org/10.1038/nature13774, 2014.

Kusaka, H., Kondo, H., Kikegawa, Y., and Kimura, F.: A simple single-layer urban canopy model for atmospheric models: comparison with multi-layer and slab models, Bound.-Lay. Mete- orol., 101, 329-358, https://doi.org/10.1023/A:1019207923078, 2001.

Kwok, R. H. F., Napelenok, S. L., and Baker, K. R.: Implementation and evaluation of $\mathrm{PM}_{2.5}$ source contribution analysis in a photochemical model, Atmos. Environ., 80, 398-407, https://doi.org/10.1016/j.atmosenv.2013.08.017, 2013.

Leng, C., Duan, J., Xu, C., Zhang, H., Wang, Y., Wang, Y., Li, X., Kong, L., Tao, J., Zhang, R., Cheng, T., Zha, S., and Yu, X.: Insights into a historic severe haze event in Shanghai: synoptic situation, boundary layer and pollutants, Atmos. Chem. Phys., 16, 9221-9234, https://doi.org/10.5194/acp-16-9221-2016, 2016.

Li, J., Wang, Z., Huang, H., Hu, M., Meng, F., Sun, Y., Wang, X., Wang, Y., and Wang, Q.: Assessing the effects of transboundary aerosol transport between various city clusters on regional haze episodes in spring over East China, Tellus B, 65, 20052, https://doi.org/10.3402/tellusb.v65i0.20052, 2013.

Li, J., Du, H., Wang, Z., Sun, Y., Yang, W., Li, J., Tang, X., and Fu, P.: Rapid formation of a severe regional winter haze episode over a mega-city cluster on the North China Plain, Environ. Pollut., 223, 605-615, https://doi.org/10.1016/j.envpol.2017.01.063, 2017.

Li, M., Zhang, Q., Kurokawa, J.-I., Woo, J.-H., He, K., Lu, Z., Ohara, T., Song, Y., Streets, D. G., Carmichael, G. R., Cheng, Y., Hong, C., Huo, H., Jiang, X., Kang, S., Liu, F., Su, H., and Zheng, B.: MIX: a mosaic Asian anthropogenic emission inventory under the international collaboration framework of the MICS-Asia and HTAP, Atmos. Chem. Phys., 17, 935-963, https://doi.org/10.5194/acp-17-935-2017, 2017.

Liao, J., Wang, T., Jiang, Z., Zhuang, B., Xie, M., Yin, C., Wang, X., Zhu, J., Fu, Y., and Zhang, Y.: WRF/Chem modeling of the impacts of urban expansion on regional climate and air pollutants in Yangtze River Delta, China, Atmos. Environ., 106, 204-214, https://doi.org/10.1016/j.atmosenv.2015.01.059, 2015.

Lin, C.-Y., Wang, Z., Chen, W.-N., Chang, S.-Y., Chou, C. C. K., Sugimoto, N., and Zhao, X.: Long-range transport of Asian dust and air pollutants to Taiwan: observed evidence and model simulation, Atmos. Chem. Phys., 7, 423-434, https://doi.org/10.5194/acp-7-423-2007, 2007.

Liu, H.: Transport pathways for Asian pollution outflow over the Pacific: Interannual and seasonal variations, J. Geophys. Res., 108, 8786, https://doi.org/10.1029/2002jd003102, 2003.

Mari, C.: Export of Asian pollution during two cold front episodes of the TRACE-P experiment, J. Geophys. Res., 109, D15S17, https://doi.org/10.1029/2003jd004307, 2004.

Rosenfeld, D., Sherwood, S., Wood, R., and Donner, L.: Atmospheric science. Climate effects of aerosol-cloud interactions, Science, 343, 379-380, https://doi.org/10.1126/science.1247490, 2014.

Skamarock, W. C., Klemp, J. B., Dudhia, J., Gill, D. O., Barker, D. M., Duda, M. G., Huang, X. Y., Wang, W., and Powers, J. G.: A description of the Advanced Research WRF version 3, NCAR Tech. Note NCAR/TN-475+STR, National Center for Atmospheric Research, Boulder, Colorado, USA, 125 pp., 2008.

Sun, Y. L., Wang, Z. F., Fu, P. Q., Yang, T., Jiang, Q., Dong, H. B., Li, J., and Jia, J. J.: Aerosol composition, sources and processes during wintertime in Beijing, China, Atmos. Chem. Phys., 13, 4577-4592, https://doi.org/10.5194/acp-13-4577-2013, 2013.

Tao, M., Chen, L., Xiong, X., Zhang, M., Ma, P., Tao, J., and Wang, Z.: Formation process of the widespread extreme haze pollu- 
tion over northern China in January 2013: Implications for regional air quality and climate, Atmos. Environ., 98, 417-425, https://doi.org/10.1016/j.atmosenv.2014.09.026, 2014.

Wang, H., Xu, J., Zhang, M., Yang, Y., Shen, X., Wang, Y., Chen, D., and Guo, J.: A study of the meteorological causes of a prolonged and severe haze episode in January 2013 over central-eastern China, Atmos. Environ., 98, 146-157, https://doi.org/10.1016/j.atmosenv.2014.08.053, 2014.

Wang, J., Zhao, B., Wang, S., Yang, F., Xing, J., Morawska, L., Ding, A., Kulmala, M., Kerminen, V.-M., Kujansuu, J., Wang, Z., Ding, D., Zhang, X., Wang, H., Tian, M., Petäjä, T., Jiang, J., and Hao, J.: Particulate matter pollution over China and the effects of control policies, Sci. Total Environ., 584-585, 426447, https://doi.org/10.1016/j.scitotenv.2017.01.027, 2017.

Wang, Y., Yao, L., Wang, L., Liu, Z., Ji, D., Tang, G., Zhang, J., Sun, Y., Hu, B., and Xin, J.: Mechanism for the formation of the January 2013 heavy haze pollution episode over central and eastern China, Sci. China Earth. Sci., 57, 14-25, https://doi.org/10.1007/s11430-013-4773-4, 2013.

Wang, Z., Li, J., Wang, Z., Yang, W., Tang, X., Ge, B., Yan, P., Zhu, L., Chen, X., Chen, H., Wand, W., Li, J., Liu, B., Wang, X., Wand, W., Zhao, Y., Lu, N., and Su, D.: Modeling study of regional severe hazes over mid-eastern China in January 2013 and its implications on pollution prevention and control, Sci. China Earth. Sci., 57, 3-13, https://doi.org/10.1007/s11430-013-47930, 2013.
Wei, Y., Li, J., Wang, Z.-F., Chen, H.-S., Wu, Q.-Z., Li, J.-J., Wang, Y.-L., and Wang, W.: Trends of surface $\mathrm{PM}_{2.5}$ over BeijingTianjin-Hebei in 2013-2015 and their causes: emission controls vs. meteorological conditions, Atmos. Ocean. Sci. Lett., 10, 276 283, https://doi.org/10.1080/16742834.2017.1315631, 2017.

Wu, D., Bi, X., Deng, X., Li, F., Tan, H., Liao, G., and Huang, J.: Effect of atmospheric haze on the deterioration of visibility over the Pearl River Delta, Acta Meteorol. Sin., 21, 215-223, 2007.

Yang, Y., Liu, X., Qu, Y., Wang, J., An, J., Zhang, Y., and Zhang, F.: Formation mechanism of continuous extreme haze episodes in the megacity Beijing, China, in January 2013, Atmos. Res., 155, 192-203, https://doi.org/10.1016/j.atmosres.2014.11.023, 2015.

Zhao, X. J., Zhao, P. S., Xu, J., Meng,, W., Pu, W. W., Dong, F., He, D., and Shi, Q. F.: Analysis of a winter regional haze event and its formation mechanism in the North China Plain, Atmos. Chem. Phys., 13, 5685-5696, https://doi.org/10.5194/acp13-5685-2013, 2013.

Zhu, B., Su, J., Han, Z., Yin, C., and Wang, T.: Analysis of a serious air pollution event resulting from crop residue burning over Nanjing and surrounding regions, China Environ. Sci., 30, 585-592, 2010 (in Chinese). 